ORIGINAL ARTICLE

\title{
Comparison of hemorrhoidectomy by conventional technique and suture less technique.
}

\author{
Muhammad Bilal', Viqar Aslam², Zaheer ud Din ${ }^{3}$, Waqas Jan ${ }^{4}$
}

Article Citation: Bilal M, Aslam V, Zaheer ud Din, Jan W. Comparison of hemorrhoidectomy by conventional technique and suture less technique. Professional Med J 2022; 29(2):145-149. https://doi.org/10.29309/TPMJ/2022.29.02.6480

\begin{abstract}
Objective: To compare the surgical outcomes of hemorrhoidectomy performed by suture less with conventional technique. Study Design: Randomized Clinical Trial. Setting: DHQ Charsadda. Period: 15 May 2017 to 30 June 2018. Material \& Methods: This was done on 60 admitted patients with grade 3 or grade 4 prolapsed hemorrhoids with failed conservative treatment from. These Patients were randomly assigned using sealed opaque envelopes containing computer-generated random numbers into two groups, Group A, who would undergo scissors excision and group B would undergo diathermy without ligation. Postoperative follow up was carried till 6 months. Data were collected and analysis by using SPSS version 23. Chi square test was used to compare at level of significance <0.005. Results: Median age of Group A was 52 years with range 33-65 while In group B age ranged from 34-65 with a median age was 51 years. Length of hospital stay in both groups ranged 1-5 days, with a median of 3 days. Every patient experienced different pain at different levels but there was no statistical difference in the severity of postoperative pain between the two groups. Follow up results showed five subjects from Group A and two from Group B had mild anal strictures, which dilated with bulk laxatives alone. Conclusion: There are no significant differences in the surgical outcomes of hemorrhoidectomy done by both techniques.
\end{abstract}

Key words: Hemorrhoidectomy, Outcome, Surgical.

\section{INTRODUCTION}

Hemorrhoidectomy is a surgical procedure to treat grade 3 and 4 hemorrhoids. Excision of prolapsed hemorrhoids is notorious for severe postprocedural pain and discomfort. Procedures to treat hemorrhoids includes ligation, excision (Milligan Morgan hemorrhoidectomy), Rubber band ligation, injection sclerotherapy, infrared photocoagulation and cryotherapy. ${ }^{1-4}$ Surgical excision is most popular and widely practicing procedure, yet it is related with considerable post-operative pain and discomfort. Clinical trials and studies have been done for the last two decades concentrating on reducing post hemorrhoidectomy pain. ${ }^{4}$

Several modification in surgical techniques have been made concerning the post procedural pain i-e; diathermy, coagulation, hormonic scalpel, ligasure system and use of stapling devices.
Studies showed that Ligation, Hormonic scalpel and Diathermy techniques resulted in less post-operative pain, wound healing and better satisfaction. ${ }^{1,5}$ There are very few studies ${ }^{6,7}$ have been done on comparing new with the conventional surgical procedure and showing their part in reducing post-operative pain. On literature search it was found that no such study done on the local population. Due to very few studies internationally and lack of study locally this study is aiming to compare the surgical outcomes of hemorrhoidectomy performed by scissors excision Ligature and diathermy without ligation as these procedures are performed routinely. These will help the surgeons as well as the patient's regards to reduce the post procedural pain.
1. FCPS (General Surgery), Senior District Surgeon, $\mathrm{DHQH}$ Charsadda

2. FCPS (General Surgery), Associate Professor General Surgery, LRH PGMI.

3. FCPS (General Surgery), Consultant Surgeon, DHQH Charsadda.

4. FCPS (General Surgery), Consultant Surgeon, DHQH Charsadda.
Correspondence Address:

Dr. Viqar Aslam

Associate Professor General Surgery, PGMI LRH.

surgeonvat@gmail.com

Article received on: Accepted for publication:
$16 / 03 / 2021$ $10 / 07 / 2021$ 


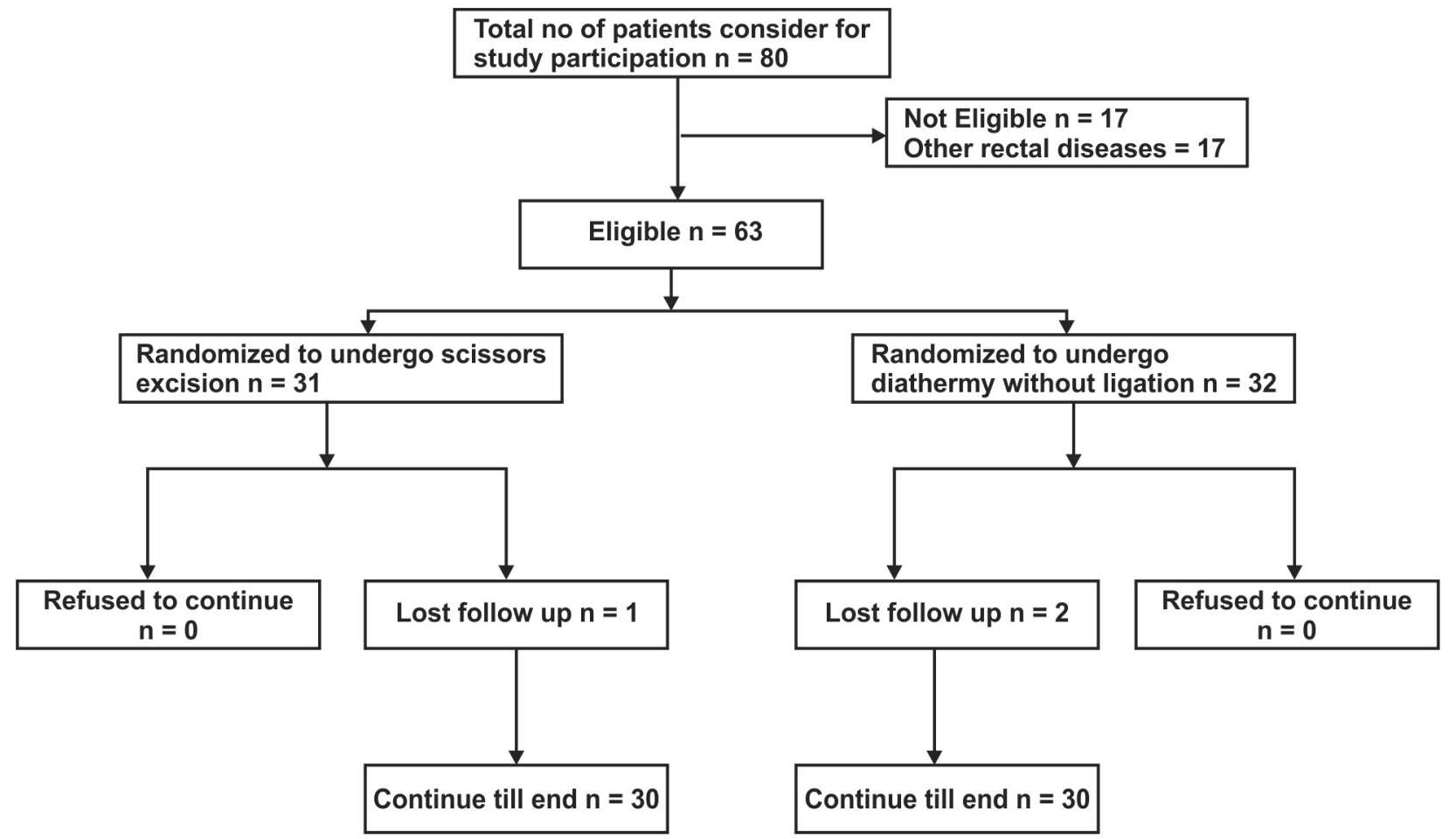

Figure-1. Flow chart.

\section{MATERIAL \& METHODS}

This is the randomized clinical trial done in tertiary care hospital (Charsadda), General surgery unit after the approval of Ethical Committee of the institution (letter no3469/110/DHQ Hospital CHD Dated 11-05-17) from June 2017 to June 2018. Eligible patients $(n=63)$ were randomly assigned using sealed opaque envelopes containing computer $\square$ generated random numbers into two groups Figure-1. Group A, (31 patients) who would undergo scissors excision and group $B$ (32 patients) would undergo diathermy without ligation. Patient's age 25 years to 70 years, having no other rectal or anal disease, and completed the 6 months follow up were included. An informed written consent was taken from all patients included in study. Pre-operatively all patients were admitted a day before surgery for pre-operative management and relative investigations. Next day surgery performed and then post-operative management done in ward and on next day most patients discharged after confirming first bowel movement and having no other post-operative complications. Procedure for group A contained
$0.5 \%$ bupivican with $1: 20,000$ adrenaline solution infiltrated into the hemorrhoids and then dissected with scissors, pedicles ligated and hemorrhoidal tissue dissected with securing inter between skin. Hemostasis has been secured by diathermy. All patients each had three hemorrhoids removed.

Group B, there was no adrenaline or local anesthetic used and hemorrhoidal tissue dissected by diathermy coagulation mode set at a high value of seven. No suture ligation of pedicles done and inter-dissection skin and mucosal bridges preserved. Among all patients combined 19 patients had procedure under General anesthesia and 8 patients having procedure under Spinal anesthesia. All patients each had three hemorrhoids removed. Anal dilation with packs was not used in both cases.

In post-operative management all patients were administered with intramuscular pethidine $\mathrm{HCl}$ (50-75mg) and oral naproxen sodium (550 mg $\mathrm{BD}$ ) as needed by patients. $2 \%$ topical lignocaine gel and liquid paraffin mixture also used. Patients 
were discharged with prescription of bulk forming laxatives continued for indefinite time, oral analgesics for 10 days and no antibiotics were added. A simple Performa was given to patients who were blind to the procedure performed on them, containing linear analog scale of 0-10 and patients were asked to score 0 as no pain to 10 as worst pain experienced. It also contained daily oral or I.V analgesic use and daily bowl movements for the first 8 post-operative days. Patients were facilitated by investigator in case of any query. Performas were submitted to investigator. During follow up patients were examined as out-patients at 6 weeks, 3 months and 6 months. Surgeon was asked to note the following; palpable fibrosis as stricture at healed hemorrhoidectomy site. 2 patients from Group B and 1 patient from Group A were lost during follow-up. Data were collected and analysis by using SPSS version 23 . Chi square test was used to compare at level of significance $<0.005$. Results were expressed in range and median.

\section{RESULTS}

Total of 60 patients after follow up lost were included in study, in group A remaining 30 patients on excision was performed age ranging 33-65 and their mean age 51 years. In group B age ranged from 34-65 and the mean age was 50 , they went through diathermy without ligation. There were 21 male in Group A while 18 in Group B. (Table-I) This gender imbalance was due to chance but it has benefit to look at the gender differences regarding pain.

Length of procedure for Group A was range from $15-45$ minutes with median of 25 minutes while for Group B it was ranged between 10- 40 minutes with a range of 15 minutes $(p=0.04)$. (Table-II) Patients from group A stayed for 2-5 day postoperative in hospital and the other group stayed for 1-5 days post operatively with a median of 3 days.

Every patient experienced different pain at different levels, though there was no significant difference in pain in both groups. Group B experienced a high level of pain on 3rd postoperative day during bowel movements. Pain score and mean for group A was 6 (0-9) $P=0.06$ while the score and mean for group $B$ was lesser and that was 4(0$7) ; P=0.06$. There was no significant difference between the genders scores regarding severity of pain in both groups. (Table-III)

Follow up results showed five subjects from Group A and two from Group B had mild anal strictures, which dilated with bulk laxatives alone. No patient with secondary or reactionary bleeding in both groups was noted. Wounds of all patients were healed completely, and all patients are fully continent.

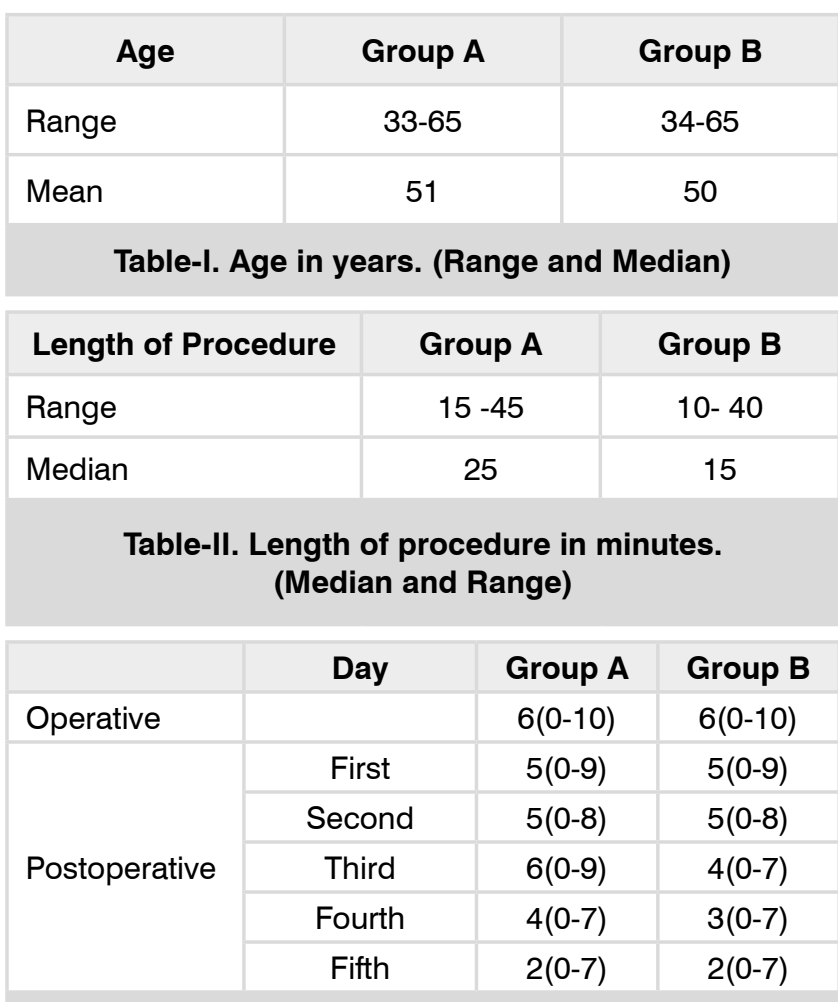

Table-III. Pain score. (Mean and Range)

\section{DISCUSSION}

Postoperative pain after hemorridal tissue removal is a matter of concern for both patients and surgeons. Various modifications in the surgical procedures had been adopted to reduce the pain but not had been successful universally. ${ }^{1,6}$

The difference between the pain experienced at rest by group $A$ and group $B$ was insignificant. Group B (diathermy coagulation) experienced high pain during bowel movements than group $A$. 
This may be due to the diathermy coagulation resulted in the necrosis of the anal wall, pain has been reduced postoperative but it increased once the sloughing of the scar tissue was taking place. On the other hand in group A pain was subsiding as the anal wall was healing gradually day by day. However both groups were taking the same oral analgesics post operatively. Moreover, It has been reported that diathermy coagulation resulted in shrinkage of hemorrhoidal tissue thus the denudation of the anal wall was limited to the small area. There was no bleeding during procedure. These results are in accordance to the studies done by Parks ${ }^{8}$ and watts. ${ }^{9}$

Pain is defined as a subjective experience to a harmful stimulus ${ }^{4}$, and it was noted in our study that there were subjects in both groups who experienced severe pain or either no pain at all. There were imbalance in the sex ratio in both groups despite randomization but no statistical differences in pain scores and postoperative analgesics demand was observed in between both genders of either Group A or Group B. No difference was found in length of the procedure and stay postoperatively between patients of both groups. These results are in accordance to results of Parks ${ }^{8}$ and Ibrahim. ${ }^{10}$ There were no differences in the occurrence of complications after both procedures. The use of either method did not seem to affect the duration of surgery, severity of pain, length of stay, or patients' satisfaction, which were similar in both groups.

\section{CONCLUSION}

There are no significant differences in the surgical outcomes of suture less technique with conventional hemorrhoidectomy.

Copyright@ 10 July, 2021.

\section{REFERENCES}

1. Heng G, Tan KY. Excision Hemorrhoidectomy: New methods to improve the outcomes of an old technique. Jentashapir J Cell Mol Biol. 2016; 7(3):e34119. doi: 10.17795/jjhr-34119.
2. M Trompetto, G Clerico, G F Cocorullo, P Giordano, F Marino, J Martellucci, G Milito, M Mistrangelo, C Ratto. Evaluation and management of hemorrhoids: Italian society of colorectal surgery (SICCR) consensus statement. Tech Coloproctol 19, 2015 Oct; 19(10):567-75. https://doi.org/10.1007/s10151-015$1371-9$.

3. Tin SS, Wiwanitkit V. Score to predict pain after excisional hemorrhoidectomy. Int $\mathrm{J}$ Colorectal Dis 2015 Apr; 30(4):575. https://doi.org/10.1007/ s00384-014-2022-8.

4. Brown SR, Tiernan JP, Watson AJM, Biggs K, Shephard $\mathrm{N}$, Wailoo $\mathrm{AJ}$, et al. Haemorrhoidal artery ligation versus rubber band ligation for the management of symptomatic second-degree and third-degree haemorrhoids (HubBLe): A multicenter, openlabel, randomized controlled trial. Lancet. 2016 Jul 23; 388(10042):356-364. doi: 10.1016/S01406736(16)30584-0. Epub 2016 May 25.

5. Ruiz-Tovar J, Duran M, Alias D, Manso B, Moreno A, Nevado C. et al. Reduction of postoperative pain and improvement of patients' comfort after MilliganMorgan hemorrhoidectomy using topical application of vitamin E ointment. Int J Colorectal Dis $2016 \mathrm{Jul}$; 31(7):1371-2. https://doi.org/10.1007/s00384-015-24834.

6. Hetzer FH, Demartines N, Handschin AE, Clavien P. Stapled vs Excision hemorrhoidectomy: Long-term results of a prospective randomized trial. Arch Surg. 2002; 137(3):337-340. doi:10.1001/archsurg.137.3.337.

7. McKenna, Nicholas P, Lightner, Amy, Habermann, Elizabeth B, Mathis, Kellie L. Hemorrhoidectomy and excision of skin tags in IBD: Harbinger of doom or simply a disease running its course? Diseases of the Colon \& Rectum. 2019; 62: 1505-11.

8. Parks AG. The surgical treatment of haemorrhoids. $\mathrm{Br}$ J Surg 1956;43:337-51.

9. Watts JM, Bennett RC, Duthie HL, GoligherJC. Healing and pain after haemorrhoidectomy. Br J Surg 1964; 51:808-17.

10. Ibrahim S, Tsang C, Lee YL, Eu KW, Seow-Choen F. Prospective, randomized trial comparing pain and complications between diathermy and scissors for closed hemorrhoidectomy. Dis Colon Rectum 1998; 41:1418-20. 


\section{AUTHORSHIP AND CONTRIBUTION DECLARATION}

\begin{tabular}{|c|l|l|l|}
\hline No. & \multicolumn{1}{|c|}{ Author(s) Full Name } & \multicolumn{1}{|c|}{ Contribution to the paper } & Author(s) Signature \\
\hline 1 & Muhammad Bilal & $\begin{array}{l}\text { Data collection, Analysis of } \\
\text { literature review. } \\
\text { Research designing, } \\
\text { Literature review of drafting. }\end{array}$ \\
\hline 3 & Viqar Aslam & $\begin{array}{l}\text { Objective setting \& Drafting. } \\
\text { Zaheer ud Din }\end{array}$ & $\begin{array}{l}\text { Data collection \& Paper write } \\
\text { up. }\end{array}$ \\
\hline 4 & Waqas Jan & \\
\hline
\end{tabular}

